\title{
Social media y comercio electrónico. Pinterest como nueva herramienta comunicacional ${ }^{1}$
}

\section{Social media and e-commerce electronic: Pinterest as a new}

\section{communication tool}

\author{
Joan Francesc Fondevila Gascón. Universitat Abat Oliba CEU (UAO), Universitat Oberta de Catalunya (UOC) y \\ Centro de Estudios sobre el Cable (CECABLE)
}

Carolina Herrando Soria. Universitat Oberta de Catalunya (UOC) y Centro de Estudios sobre el Cable (CECABLE)

Ana Beriain Bañares. Universitat Abat Oliba CEU (UAO)

Josep Lluís del Olmo Arriaga. Universitat Abat Oliba CEU (UAO)

Recibido: 16-I-2012 - Aceptado: 05-VI-2013

Resumen:

Internet ha puesto al alcance de la sociedad las herramientas necesarias para convertir al individuo en un usuario activo. La tecnología ha transformado la forma lineal y rígida en la que se recibía la información, para dar paso a un flujo de contenidos hipertextual y bidireccional. Esta investigación cualitativa pretende vislumbrar si la red social Pinterest podría actuar como una herramienta comunicacional para fomentar el comercio electrónico. Hemos estudiado la percepción de los internautas sobre esta red social. De esta manera, a través de la observación online y de la entrevista en profundidad virtual, bajo el método de comparación constante de la teoría fundamentada, concluimos que los internautas perciben a Pinterest más como herramienta comunicacional que de $e$-commerce.

Palabras clave:

Pinterest; comunicación 2.0; social media; comercio electrónico; social commerce

Abstract:

Internet has facilitated to society the tools to convert the individual into an active user. Technology has transformed the linear and rigid procedure in which we received the information, to make way for a bidirectional and hypertextual flow content. The purpose of this qualitative research is to glimpse if the social network Pinterest could act as a communication tool to promote the ecommerce. We have studied the perception that Internet users have on this social network. Therefore, through online observation and virtual in-depth interviews, under the constant comparison method of grounded theory, we conclude that users perceive Pinterest more than a communicative tool than an ecommerce tool.

Keywords:

Pinterest; 2.0 communication; social media; ecommerce; social commerce

1 Grupo de Investigación sobre Periodismo Digital y Banda Ancha (Sistemas de producción del periodismo digital español en el contexto internacional e impacto de la banda ancha) y Grupo de Investigación sobre Psicocreatividad de la Universitat Abat Oliba CEU, Ayudas a la Investigación 2013. CEU-Banco Santander. Código proyecto: B112AR08. 


\section{Introducción}

Apenas tres años después de su aparición en Internet, Pinterest, red social directa ${ }^{2}$ (caracterizada por la horizontalidad y la igualdad de condiciones en la información compartida), se ha consolidado entre las redes sociales más populares (ONTSI, 2012), con la peculiaridad de tener una aparente vinculación con el social shopping, puesto que Pinterest actúa como un nodo de la red con infinitas interconexiones a páginas de e-commerce; las interrelaciones que allí florecen fomentan el consumo en línea a través de recomendaciones de productos y listas de deseos.

El panorama cibernético actual nos sitúa en la era del prosumidor (productor + consumidor), un consumidor activo y comprometido, que no sólo compra, sino que crea contenidos, recomienda y asesora a la sociedad virtual sobre aquellos productos que le gustan o que utiliza. En definitiva, un individuo al que le gusta compartir sincera y abiertamente sus ideas con un público desconocido, por lo que esos consejos no tienen por qué ser tendenciosos o estar sesgados. A los usuarios de Pinterest les gusta compartir (eMarketer, 2012), y esa es una de las esencias del social commerce, es decir, el comercio electrónico a través de redes sociales.

De esta manera, con la inclusión de las web 2.0, en el siglo XXI se han incrementado este tipo de relaciones horizontales. Los grupos sociales o individuos a los que recurrimos cuando queremos realizar una compra y necesitamos consejo o simplemente cuando requerimos más información sobre el producto son los denominados social digital shoppers u online shoppers (Capgemini, 2012).

Por tanto, la comunicación empresarial trata de adaptarse a la situación introduciendo al máximo sus contenidos en las redes sociales, para que éstos sean divulgados por la red, a través de los usuarios, de manera natural según los deseos, necesidades o búsquedas de los internautas. El hecho de que el $52 \%$ de consumidores prefieran realizar las compras mediante fórmulas digitales, sea en entornos virtuales o físicos, es revelador (comScore, 2013). Ello puede inspirar el potencial de Pinterest como agente dinamizador y promotor del e-commerce, a la manera de herramienta comunicativa que ayude la compra online.

El marco teórico y de referencia en el que se sitúa esta investigación persigue la creencia de la analogía entre Pinterest y una herramienta comunicacional, dado que los datos demuestran una vinculación entre esta red social y las compras online. Como señala Rachel Tipograph, directora de social media en la cadena de tiendas de ropa Gap, citada por Cantalapiedra (2012), cualquier compañía interesada en el comercio electrónico debe prestar mucha atención a Pinterest.

2 Las redes sociales indirectas son los foros y los blogs, en los que un usuario controla el debate y no necesariamente los perfiles son públicos. 
En esta investigación nos hemos propuesto ir más allá de los datos cuantitativos para analizar cualitativamente qué es lo que realmente advierten los internautas, cuál es la impresión que tienen sobre Pinterest, cómo perciben las interacciones comunicativas que surgen en esta red y su vinculación con el $e$-commerce.

Pese a la juventud de Pinterest han surgido algunas incursiones epidérmicas sobre su introducción en el mercado y los tipos de consumidores que allí se forman (Fonoll, 2012; Núñez, 2012) y su impacto en la educación (Álvarez, 2012). Sin embargo, son pocos los estudios científicos sobre esta red social. De ahí que sea necesario definir con mayor precisión las características que pueden situar a Pinterest como una herramienta de comunicación que promueva el consumo en línea.

En comparación con el resto de redes sociales, encabezadas por Facebook (Fondevila y Beriain, 2012) y Twitter, Pinterest se caracteriza por su impacto visual y su sencillez. Se trata de una red social en la que no se fomenta la publicidad, al menos en el momento de la elaboración de este estudio. Curiosamente, pese a su vocación no lucrativa, Pinterest se está convirtiendo en un punto de referencia para el e-commerce.

Desde su creación, en marzo de 2010, como una red privada en versión beta, en la que se necesitaba una invitación para poder acceder, sus creadores, Ben Silbermann y Evan Sharp, la han visto crecer vertiginosamente. El marketing ha sido más relevante que la ingeniería para propulsar esa red entre la cornucopia de redes existentes en Internet. Pinterest se ha convertido en un galvanizado del social commerce (Fondevila, 2012b), gracias a su contenido hipersegmentado y las recomendaciones de los usuarios, que dan lugar a unas tasas de conversión elevadas.

Probablemente esta premisa de privacidad, intimidad y exclusividad haya sido una de las claves del acelerado desarrollo de Pinterest, convertida en poco más de dos años en la tercera red social más popular de Estados Unidos. Sólo Facebook y Twitter superaban a Pinterest, devenida herramienta de redirección del tráfico en beneficio del comercio electrónico (Villar, 2012), ya que sus usuarios eran más propensos (un 10\% más) a la compra que los provenientes de otras redes sociales, y mucho más que los provenientes de otras páginas web (un 70\% más). El gasto de los usuarios de la nueva red (80 dólares de promedio) era el más elevado de las redes sociales, y suponía más del doble que el procedente de Facebook. Además, Pinterest generaba el mismo tráfico que Twitter a las tiendas en línea. El impacto de las redes sociales es evidente en el comercio electrónico, como se ha demostrado en el sector de la moda (Fondevila, Del Olmo, Bravo, 2012).

El hecho de que la red visual aumentase el número de usuarios un 3.29\% (Cuadro 1) de septiembre a diciembre de 2011 (Solis, 2012) refleja el sorprendente crecimiento de esa red. 
Cuadro 1. Evolución de audiencia de Pinterest en 2011

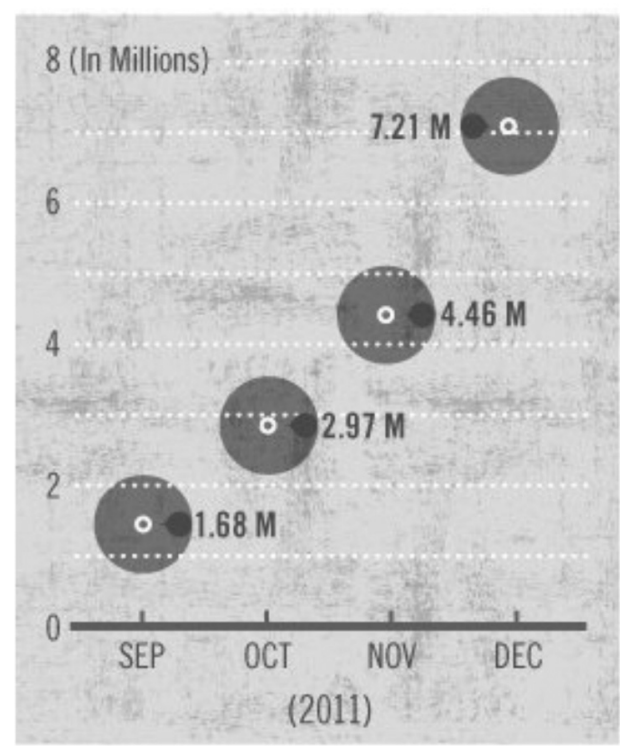

Fuente: Compete.com (2011)

Uno de los aspectos llamativos de Pinterest es que crece en todos los países censados (Cuadro 2). Con todo, esa red social se ha comportado de una manera diferente en diversos países europeos. Los que más crecen son Alemania y España, con Italia en un segundo escalafón y Reino y Francia en el tercero. 
Cuadro 2. Evolución de audiencia de Pinterest en España (2011-12)

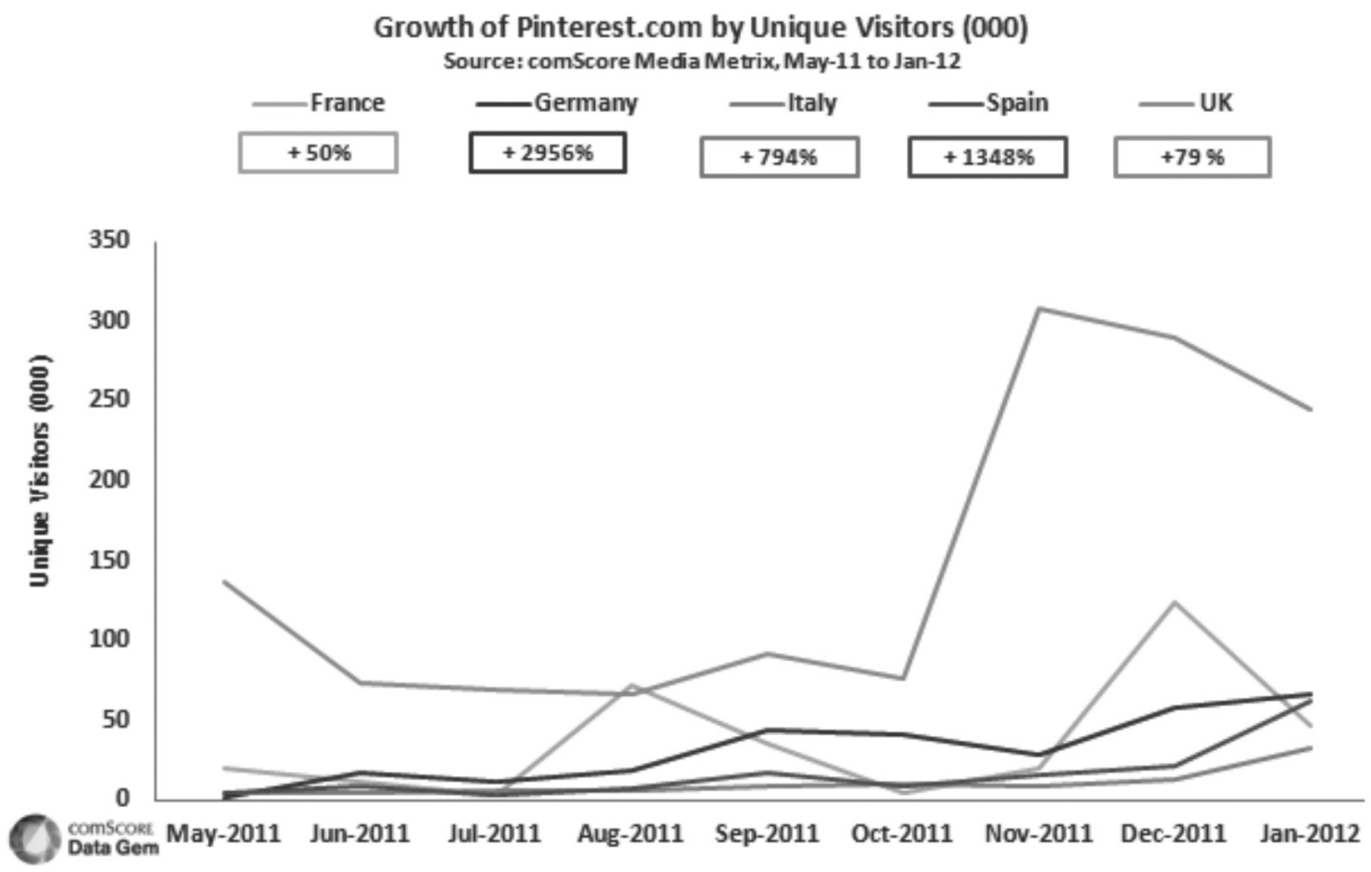

Fuente: comScore (2012)

Asimismo, es remarcable que Pinterest sea la red social de compartir imágenes que más rápidamente ha alcanzado diez millones de visitantes mensuales en Estados Unidos, y que aporta más tráfico que Youtube, Reddit, Google+ y LinkedIn (Caines, 2012).

Se puede afirmar, por ende, que Pinterest ha despuntado desde su inicios, pero no sólo creándose un espacio entre las redes social más relevantes, sino posicionándose como una red social vinculada al e-commerce. Así, los consumidores online seguían a mediados de 2012 una media de 9,3 comercios en Pinterest, 8,5 en Twitter y 6,9 en Facebook, cifras significativas teniendo en cuenta la juventud de la red social visual (Marketing Directo, 2012).

Este fenómeno puede ser calificado de sorprendente, pese a la tendencia de Internet a la exponencialidad en una dinámica de flujo constante de contenidos, es decir, de cloud journalism (Fondevila, 2010a). A la luz de esta realidad, han aparecido competidores como Fancy, Pinspire, PicPlz, Instagram, Tumblr, Polyvore, Discoveredd, Juxtapost, PicYourLife, Evernote, Pocket, Springboard, OneNote, Clipboard o Murally (Roig, 2012). Para todos estos sitios web 2.0, el objetivo común es compartir gustos y deseos del consumidor a través de imágenes. Y, dado que desde sus inicios Pinterest se ha vinculado al 
social commerce (en cambio, su antecesor Flickr nunca se ha destacado en ese sentido), sus competidores comienzan a incluir la venta directa desde la misma página web. Así, los usuarios de Fancy no sólo pueden subir a la red las fotos que les gustan, sino que también cuentan con la opción de adquirir los productos que aparecen en esas imágenes fijas desde la propia red social.

Otra diferencia entre Fancy y Pinterest es que el público de la primera es más masculino, mientras que en Pinterest la mayor parte de análisis y referencias reflejan una clara tendencia hacia al público femenino (McCracken, 2012; Caines, 2012; Szymanski, 2012; Ledbetter, 2012; eMarketer, 2012), con cifras como que el 79\% de los usuarios de Pinterest son mujeres y que el $32 \%$ de compradores norteamericanos online han realizado alguna compra como resultado de haber visualizado una imagen en una red social visual, sea Pinterest, Juxtapost, Discoveredd, Fancy o Polyvore (Cuadro 3).

Cuadro 3. Compra en línea tras haber visto una imagen en una red social visual (2012)

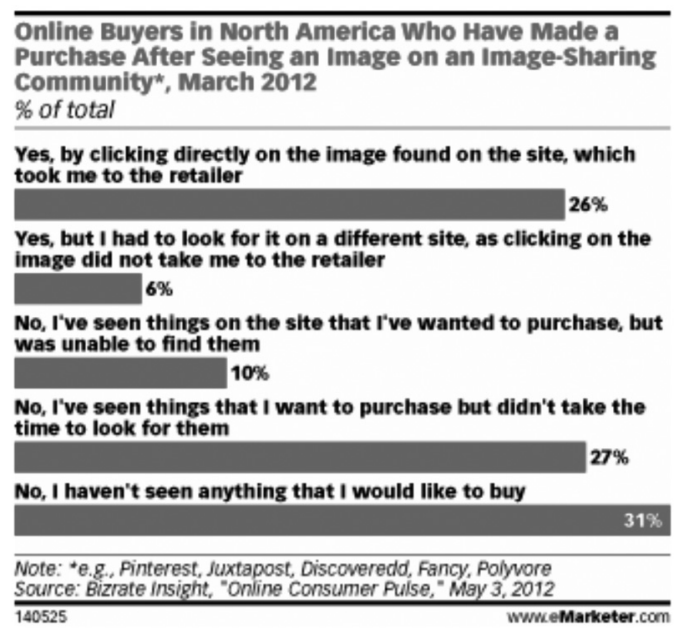

Fuente: eMarketer (2012)

Esos datos conducen a plantearse que la comunicación que se dé en las redes sociales de carácter marcadamente visual (en nuestro caso, Pinterest) será fundamental para poder designar a ésta como una herramienta comunicacional para el comercio electrónico o para el social commerce. De esta manera, bajo el marco teórico de los estudios de publicidad y relaciones públicas, hallamos diversas características a analizar en Pinterest. 


\subsection{Pinterest, una red social visual}

Pinterest es una red social basada en la imagen, que proporciona las herramientas necesarias para que el usuario organice, conserve, comente y comparta imágenes y videos clasificándolos por tableros o carpetas de archivos, categorizados por la temática que el consumidor elija.

No obstante, podemos encontrar definiciones diversas sobre Pinterest que nos pueden ayudar a comprender mejor cuál es la interpretación que los usuarios hacen sobre la misma. Así, a Pinterest se la ha definido como un tablón de ideas, inspiraciones, imágenes y deseos, como un escaparate (Fonoll, 2012), como una oportunidad para la hiperpersonalización (Caines, 2012), como un lugar para conseguir inspiración sobre qué comprar (Bizrate Insights, 2012) o como una lista de deseos de consumo para mujeres (McCraken, 2012). Pese a que en su origen con espíritu no lucrativo, Pinterest se ha convertido en la red social visual de referencia, con promoción de la compra de los productos allí publicados.

Se puede también enmarcar una definición de Pinterest bajo el método AIDA (por sus siglas en inglés, attention, interest, desire, action), utilizado por diversos autores (Kotler y Armstrong, 2003; Moore, 2005), ya que las imágenes mostradas en esta red social buscan llamar la atención del usuario, despertando su interés y su deseo de adquisición para motivar la acción de compra, al igual que puede actuar un mensaje publicitario o un escaparate.

Estas características denotan que la comunicación de Pinterest, en casos de empresas, está conectada a unos objetivos de venta online, ya que los contenidos de Pinterest buscan estimular la atención de los cibernautas para que compartan dichos contenidos o para redirigir tráfico a las webs; y, asimismo, estimulan el interés y el deseo con una imagen y estilismo cuidados que hacen que los usuarios se apropien de las imágenes por relación a un estilo de vida similar, deseado o buscado. Al mismo tiempo, gracias a la sencillez de Pinterest, combinada con la rapidez de Internet, los contenidos de esta red social logran que los internautas pasen a la acción, ya sea pineando una imagen o dirigiéndose a la web de donde parte.

\subsection{El usuario activo}

Como hemos observado, aunque aparecen grupos sociales relevantes que indican que Pinterest puede ser una lanzadera para el e-commerce, su objetivo principal radica en posibilitar que sus usuarios compartan imágenes y las clasifiquen a su antojo; no obstante, con el fin de comprender cuál es la visión de dichos usuarios sobre esta red social, debemos también desglosar cuáles son su propiedades.

El usuario de Pinterest forma parte de la Sociedad de la Banda Ancha (Fondevila, 2012a), una sociedad en la que la disponibilidad de acceso a la red tiende a universalizarse y la experiencia de navegación está garantizada. En ese entorno, las empresas over the top (proveedoras de aplicaciones y contenidos, como Pinterest) y los operadores de telecomunicaciones tienden a aliarse para obtener provecho de la virtualidad. El consumidor está formado e informado en el uso de 
Internet, que cuenta con el acceso y conocimientos necesarios para conectarse a la red. La audiencia de Internet es más activa, predispuesta al intercambio, a opinar y aconsejar, a contribuir en una dinámica open source, a redistribuir contenidos e incluso a crear su identidad a partir de lo que va publicando, de ese rastro constante que va dejando en las diversas redes sociales. Así pues, el usuario de Pinterest se comunica, principalmente, a través de mensajes visuales.

Por otro lado, a partir de los datos recogidos en la investigación cualitativa, podemos subrayar también que el perfil de estos individuos se encasillaría en una predominancia del género femenino. Así, los datos sobre tráfico y los datos demográficos de Pinterest (Cuadro 4) reflejan que el público es básicamente femenino, la edad media de los usuarios se sitúa entre los 25 y los 44 años y el nivel de estudios predominante es universitario. El poder adquisitivo es de renta media-alta, factor que puede alimentar las estrategias de marketing y comerciales de las empresas.

Cuadro 4. Tráfico y datos demográficos sobre Pinterest (2012)

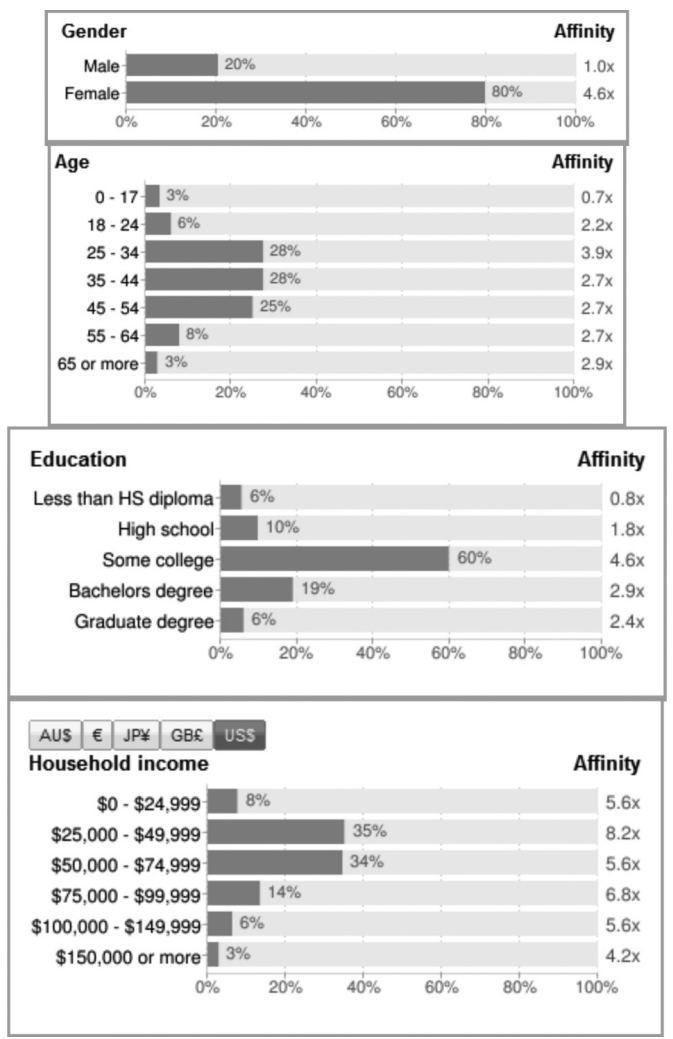

Fuente: Google Ad Planner (2012) 
Asimismo, tras los blogs (cuya evolución también está provocando la atención de las empresas), Pinterest era en 2012 la red social que más influía entre las mujeres (Cuadro 5) a la hora de hacer una compra (47\%), por delante de Facebook (33\%) y Twitter (31\%).

Cuadro 5. Principales web que influyen en la compra de las mujeres (2012)

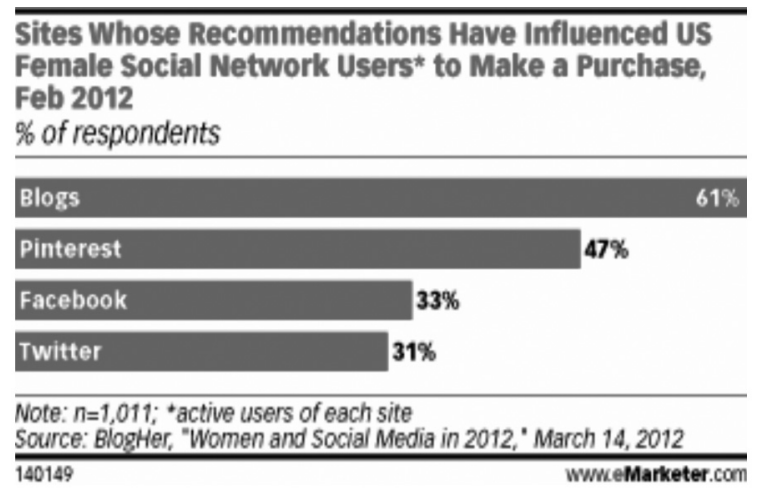

Fuente: eMarketer, 2012

Esta vinculación del usuario con el social shopping se está reforzando, y así lo reflejan parámetros como el gasto medio, el tráfico generado y la tendencia a la compra. De ahí podemos inferir que el usuario de Pinterest puede ser también un consumidor online $\mathrm{o}$, al menos, está interesado en realizar compras por Internet.

Más allá de eso, en un estudio ${ }^{3}$ que compara las razones por las que usar Pinterest frente a Facebook, los usuarios perciben una clara correlación entre la red social Pinterest y los sitios web de e-commerce (Bizrate Insights, 2012). El matiz es que, ante todo, el empleo primordial de esta red social es por entretenimiento, con el objetivo de compartir, clasificar y comentar lo que gusta el consumidor, lo que desearía tener, lo que ansía hacer. En general, impera una mentalidad consumista, ya se vaya a consumar la compra online u offline.

3 Se recolectaron datos de 7.431 compradores online de Estados Unidos y Canadá, del 9 al 17 de agosto de 2012. 
Cuadro 6. Razones para usar Pinterest y Facebook (2012)

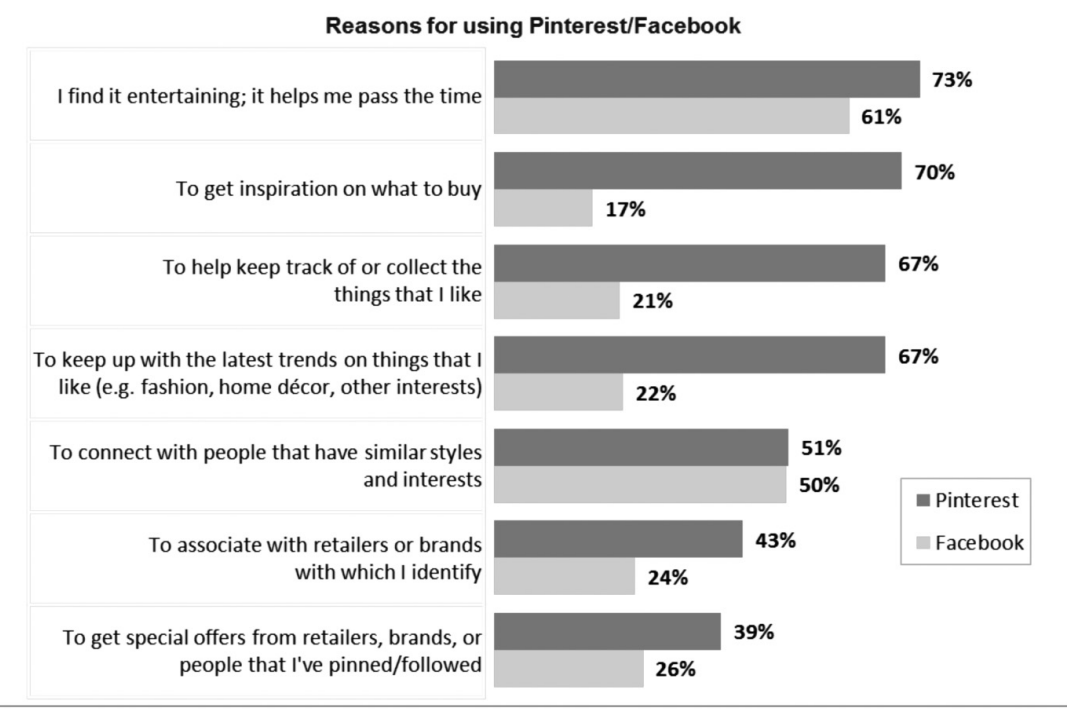

Source: Bizrate $^{\circledR}$ Insights Social Image Sharing and Online Shopping Series 3, August 2012

Q. Do you use Pinterest/Facebook for any of the following reasons?

$(n=1,248 / 4,738$ online shoppers who use Pinterest/Facebook)

Fuente: Bizrate Insights (2012)

Observamos, pues, que el usuario de la red es activo y produce y consume con cierta fluidez. Sin embargo, por lo general, a los individuos no les gusta que nadie les venda; al contrario, prefieren ser ellos mismos los que decidan comprar, aunque consciente o inconscientemente esta decisión haya sido influenciada por lobbies, por la publicidad o por otras fuentes de información (Fondevila, Carreras y Del Olmo, 2012).

Nos encontramos en la era del prosumidor, un consumidor activo dentro de la Sociedad de la Banda Ancha, que no sólo distribuye contenidos de forma desinteresada, sino que también los produce. Por tanto, el cibernauta adopta una actitud comunicativa más libre, lo que le otorga cierto poder como prescriptor de bienes y servicios, convirtiéndose en una poderosa arma comunicacional para o contra las empresas, ya que el mensaje del prosumidor no tiene por qué estar sesgado en beneficio de una marca o una compañía y, asimismo, porque, gracias a la inmediatez y a la viralidad de Internet, puede difundir contenidos y comunicaciones de forma explosiva.

Así, la web 2.0 ha propiciado la transformación de los consumidores pasivos en activos prosumidores que han impulsado importantes transformaciones en el mercado gracias al hecho de apostar por el recurso de la conversación (Islas-Carmona, 2008). La clave es conceptualizar Internet como un agente efectivo multiplicador del capital intelectual. Y ello bebe 
del manantial del universo multiplataforma, en el que proliferan los terminales para recibir, instantáneamente, cualquier contenido colgado en la red.

Por tanto, esos fundamentos en los que se asienta la sociedad de la ubicuidad son el punto de partida de la comunicación online. Así pues, el usuario de Internet ha cambiado la forma que hasta el momento tenía de comunicarse adaptándola a las tecnologías de la información y de la comunicación y a la sociedad global, que se muestra cada vez más cercana y accesible. De esta manera, gracias al hipertexto (Fondevila, 2011), la interactividad y el multimedia (Fondevila, 2010b), el individuo rompe con la linealidad comunicativa, construyendo él mismo la manera en que desea relacionarse con la información y convirtiéndose, por ende, en un actor activo.

Por tanto, el empoderamiento que adquiere la sociedad gracias a las características de Internet convierte a esta red en una herramienta comunicacional, que puede estimular o apaciguar el comercio electrónico.

\section{Metodología}

La metodología empleada en esta investigación, de carácter eminentemente cualitativo (Ruiz Olabuénaga, 1996) aunque con una base cuantitativa (con lo que entramos en la triangulación), consiste en el método empírico-analítico. La hipótesis de la investigación (H1) es que Pinterest puede actuar como un prescriptor para fomentar el e-commerce, funcionando como una herramienta comunicativa que ayuda e impulsa la compra online.

La metodología utilizada combina diversas fuentes. Por un lado, bajo un enfoque cuantitativo, además de la información recopilada para la generación del marco teórico de esta investigación, se han analizado diferentes informes sobre consumo online y social shopping (eMarketer, Ontsi, Bizrate InSights, comScore, Google Ad Planner o Altimeter). Asimismo, bajo un enfoque naturalista, se ha llevado a cabo una investigación cualitativa, con la misión de investigar cuál es la opinión y reflexión de los internautas sobre Pinterest y cómo es percibida esta red social.

Durante el desarrollo de nuestra investigación cualitativa, bajo el método de la teoría fundamentada (Strauss y Corbin, 1998), centrada en el interaccionismo simbólico y la sociología cualitativa para aproximar teoría e investigación empírica, hemos utilizado el método de comparación constante para recopilar, analizar, codificar y categorizar los datos conforme los íbamos obteniendo. Se ha optado por este método para facilitar el proceso de minimización, es decir, maximizar las diferencias entre los casos seleccionados para analizar Pinterest. Asimismo, estos datos han sido procesados por la técnica del análisis de contenido. Y, para el codificarlos y analizarlos, hemos utilizado el software informático AtlasTi (Baugh, Hallcom y Harris, 2010).

En cuanto a las técnicas que se han utilizado en esta investigación cualitativa (la observación online y la entrevista semiestructurada), hemos podido recoger diferentes datos ayudándonos de la memoria, de las notas y del diario de campo (McLellan, MacQueen y Neidig, 2003). 
El escenario escogido para la investigación, donde se comenzó la observación online, fueron los perfiles de usuarios de Pinterest en Twitter, así como en los comentarios aparecidos en foros, noticias y blogs relacionados con nuestro objeto de estudio. De esta manera, durante cuatro meses en 2012 se ha venido observando, a través de la Red, a usuarios activos de Pinterest, para posteriormente contactar con ellos y realizar una entrevista en profundidad virtual.

Los individuos que han sido observados eran, en su mayor parte, no sólo usuarios activos de Pinterest, sino también personas vinculadas al mundo de la comunicación y las nuevas tecnologías, conocedoras (muchas de ellas) de las diferentes características y posibilidades que ofrece esta red social. Aunque los individuos observados no siempre eran los mismos, ya que dependían de si el seguimiento se hacía a través de foros, noticias, blogs o redes sociales, siempre existía un grupo de una decena de personas a las que se seguía tanto a través de Pinterest como de Twitter; eran individuos activos y participativos entre la comunidad virtual, que expresaban su opinión acerca Pinterest, de la comunicación 2.0, de marketing online, de comercio electrónico, etc., por lo que creaban un clima distendido de debate que facilitaba el poder interactuar con ellos. Eso nos permitió establecer el engagement necesario para, con posterioridad, realizar la entrevista en un clima de confianza.

Durante la observación online, comenzamos a examinar la percepción que los internautas manifestaban sobre Pinterest; y, a partir de su definición sobre esta red social, pudimos vislumbrar cuál es su percepción sobre la misma, cómo la clasifican, cuál creían que era su función principal, cómo la comparan con otras redes sociales y cómo la situaban en el ranking personal de su top of mind.

En los primeros días de observación online en las redes sociales vinculadas a Pinterest observamos cómo los usuarios daban su opinión sobre esta red social; pero fue cuando comenzamos la observación y el acercamiento hacia las diez personas que habíamos seleccionado para posteriormente realizar la entrevista cuando pudimos obtener una visión más extensa acerca de cómo era percibida la comunicación que emergía en Pinterest en relación con el ecommerce. Estos internautas estaban, de manera general, muy predispuestos al diálogo y al debate, lo que resultó de gran ayuda para realizar una observación continuada. Todos ellos estaban vinculados profesionalmente al sector del marketing y de la comunicación, por lo que sus conversaciones versaban sobre las posibilidades de Pinterest en relación con el comercio electrónico. Asimismo, con la intención de no obtener datos sesgados, se observó también la percepción de internautas sin un enlace laboral a esta materia.

En la observación de los cibernautas, pudimos descubrir que no sólo los profesionales del sector del marketing y la comunicación creían que Pinterest actuaba como un instrumento para redirigir tráfico a otras webs, sino que era una percepción generalizada, ya que les permitía poder disponer de la información ordenada y organizada por tableros, y poder recurrir a la web de origen en el momento en el que lo desearan simplemente haciendo clic en el hipervínculo. 
Al cabo de unas semanas de observación, comenzamos a crear la estructura del guión de nuestra entrevista cualitativa (Rapley, 2001). En cada investigación se plantean diferentes cuestiones, y cada una de ellas va surgiendo como resultado del campo que se ha construido (Estalella y Ardévol, 2010). Por ello, a lo largo de toda la investigación y, particularmente, de la entrevista, el investigador ha mantenido una postura flexible para adaptarse a los cambios que puedan surgir en la conversación, puesto que el investigador cualitativo no se interesa por la verdad per se, sino en perspectivas (Taylor y Bogdan, 1984). Así, el entrevistador intenta extraer una traducción más o menos honesta del modo en que los informantes se ven realmente a ellos mismos, y también a sus experiencias.

Por tanto, teniendo en cuenta esta actitud abierta, se elaboró la estructura del guión, como punto de apoyo para una entrevista semi-estructurada, dirigida o focalizada. Una vez realizado el guión, había que definir también quién o quiénes iban a ser los informantes. Para la elección de los entrevistados se contactó con las diez personas con las que habíamos alcanzado cierta confianza. En un primer momento se trató de quedar con ellos para realizar una entrevista a través de un software de comunicaciones VoIP, mediante mensajería instantánea a través de Internet, voz o video-llamada; pero, por cuestiones de disponibilidad de los individuos seleccionados, esta opción se tuvo que descartar y realizamos una entrevista administrada en línea. De esta manera, se decidió realizar las entrevistas a través de correo electrónico, enviando el guión semi-estructurado para que los usuarios pudieran contestar de la forma más abierta y distendida posible. Las preguntas fueron las siguientes: ¿Cómo definiría Pinterest? ¿Cuál es su opinión acerca de las interacciones comunicativas que surgen en esta red? ¿Percibe a Pinterest como un instrumento comunicacional para el e-commerce? ¿Por qué sí o por qué no? Bajo su punto de vista, ¿cuáles son las claves de comunicación online en redes sociales, en cuanto a $e$ commerce se refiere?

\section{Resultados}

\subsection{Pinterest como herramienta para redirigir tráfico}

Desde el comienzo de la investigación, los datos muestran que Pinterest es percibida como una red social simple, sencilla, amigable, visual y con un diseño cuidado. Ello hace de la página el lugar perfecto para organizar en la red aquellas imágenes que nos gustan, que queremos compartir o que desearíamos tener, ya sea un armario o una cámara de fotos retro. Así, los usuarios de Pinterest pueden crear a través de esta red social un perfil visual sobre sí mismos, que resuma por medio de imágenes sus gustos, sus hobbies o su estilo de vida, ya sea real o deseado.

Ante esta situación, tanto las grandes compañías como las pequeñas empresas encuentran en la página de Pinterest el lugar idóneo para promocionar su negocio y comunicar sus productos, dado que la distribución de esta red social se organiza bajo la apariencia de un escaparate de productos y sus usuarios comparten los documentos abiertamente con el 
público. Asimismo, Pinterest posibilita la introducción del precio en la esquina superior izquierda de la imagen, para que el internauta pueda verlo de un primer vistazo; y, por otro lado, aunque no se venden directamente desde la red social, las imágenes posteadas están vinculadas a su web de origen, para que el usuario, si lo desea, pueda dirigirse con facilidad a dicha página, donde puede encontrar más información sobre el producto.

Por tanto, es ahí y no en Pinterest donde la web actúa como una herramienta comunicacional para fomentar el comercio electrónico. Es decir, una vez la empresa recibe el tráfico proveniente de, entre otros sitos, Pinterest, es donde comienza su labor de información y comunicación para impulsar al internauta a realizar una compra, ya sea online o para indicarle dónde o cómo puede adquirir un determinado bien o servicio en un entorno offline.

Por tanto, hay que destacar también la presencia de las empresas en Pinterest como un usuario más, puesto que son las más interesadas en redirigir y aumentar el flujo de visitantes a su web oficial, además de mostrar y publicitar sus bienes o servicios a través de las redes sociales. De hecho, al igual que ocurre en Facebook con las páginas corporativas y los perfiles de usuarios, en noviembre de 2012 Pinterest decidió lanzar Business para que las empresas puedan crear o transformar sus perfiles y marcarlos específicamente como marcas, negocios, ONGs, publicaciones o blogs.

De esta manera, no esperan a que sean únicamente los usuarios o consumidores los que movilicen los contenidos por la red, sino que las empresas, grandes o pequeñas, tienen entre sus manos una herramienta para comunicar a la comunidad virtual sus novedades o sus productos, pero además cuentan con la posibilidad de poder viralizarlos asociados a un estilo de vida o a una forma de actuar, a través de imágenes que capten la atención de los cibernautas, que quieran archivar o compartir en sus tableros de Pinterest, porque conforman el imaginario visual que los define en esta red social.

Así pues, el propósito de las empresas en Pinterest no es estrictamente cerrar una compra, sino el dar a conocer a los internautas sus productos para que sean éstos quienes los movilicen, los compartan o los guarden. Una vez estas imágenes estén en manos del usuario, éste tendrá también el precio, la información y el hipervínculo hacia la web de origen, para que sea él mismo el que decida dar el siguiente paso. De esta manera, podríamos señalar que Pinterest da, tanto a los consumidores como a los negocios, las herramientas básicas para que la comunicación fluya de una manera abierta, simétrica y bidireccional. Así pues, Pinterest es percibido como una herramienta comunicacional que actúa como un puente para redirigir su tráfico hacia las webs de origen de las imágenes, beneficiando por ende a las empresas cuyas imágenes hayan sido pinneadas directamente desde el sitio oficial de la compañía.

Por tanto, no sólo es destacable la labor comunicativa que deben hacer las empresas, tanto en la selección de sus imágenes como una vez hayan recibido en su página web el tráfico que genera Pinterest, sino que también hay que señalar la capacidad de prescripción de los internautas, capaces no sólo de compartir documentos a través de la inmensidad de la red, sino también de producirlos, es decir, de crear contenido a su antojo, lo que puede tanto facilitar la labor de las em- 
presas como perjudicarla. De esta manera, las empresas buscan también el formar su propio perfil visual a través de Pinterest, no sólo estrictamente con sus productos, sino que, al igual que el resto de usuarios, buscan formar un imaginario que los defina.

A través de la investigación cualitativa, hemos podido ratificar también la importancia de este usuario activo en las redes sociales y hemos reafirmado su supremacía en la comunicación 2.0. Como podemos contemplar en el siguiente extracto de una de las entrevistas que se realizaron, ahora es el consumidor el que tiene el poder, el poder para informarse y formarse, el poder para comunicarse de manera simétrica, el poder para informar y viralizar, mientras que la función de las empresas es mantener una buena relación con los usuarios, ofreciendo una comunicación abierta y bidireccional para informarles y que sean ellos mismos quienes movilicen los productos por la red. Es decir, el cometido de las empresas en las redes sociales debe ser $a d h o c$, mostrar una imagen de sinceridad, amabilidad, predisposición y accesibilidad, puesto que en la Sociedad de la Banda Ancha y en el entorno social media el rey es la colectividad.

"Hay que tener en cuenta que las redes sociales no han nacido para terminar siendo entendidas como canales para la venta y sí para la conversación, compartir contenido y estar al tanto de las novedades de tus conocidos. Quien quiera vender en redes sociales a través de un e-commerce integrado debe entender que lo principal son las relaciones. Quien intente vender su producto como objetivo principal estará equivocando su estrategia. Al implementar un e-commerce en Facebook o Pinterest, estamos dando la opción al usuario de acceder a nuestros productos, sus precios y las recomendaciones de otros usuarios a través de los comentarios" (extracto de entrevista realizada el 18 de noviembre de 2012 para la investigación cualitativa).

Por tanto, la percepción que los usuarios tienen sobre Pinterest es que esta red social está estrechamente ligada al comercio electrónico, dado que su apariencia de escaparate y sus posibilidades para la difusión masiva son un buen mecanismo para dar a conocer la marca o productos de la empresa. Por tanto, se confirma la hipótesis que sostiene que esta red social es una pasarela hacia el comercio electrónico, es decir, Pinterest actúa como un enlace redirigiendo flujos de personas desde la página de la red social hacia otras páginas, hacia las webs de origen; sin embargo, la hipótesis H1 que manifiesta la posibilidad de que Pinterest sea una herramienta comunicacional para el comercio electrónico no queda demostrada, puesto que la investigación nos enfoca a puntualizar que Pinterest canaliza por sí misma la comunicación hacia las webs de venta online.

De esta manera, aunque los datos muestran una clara vinculación de esta red social con el e-commerce, no hay señales precisas que indiquen que Pinterest actúa como una herramienta comunicativa para fomentar la venta en línea, dado que las ventas no se realizan directamente desde la red social. Conforme se fueron recopilando datos durante la observación online y en las entrevistas, comenzamos a entrever que la percepción de los usuarios indica que Pinterest es una herramienta comunicacional, pero no para fomentar la venta online per se, sino para generar tráfico a las webs de empresas que, posteriormente, en función de la habilidad de éstas, puede convertirse en ventas. 
Así pues, la redirección de tráfico desde Pinterest hacia las webs de las empresas viene determinada, indirectamente, por las claves comunicativas de la red social, pero con el propósito de generar un tránsito en el flujo de visitantes a la web, donde posteriormente, la empresa deberá desplegar sus competencias con ingenio y astucia, aplicando sus herramientas para el e-commerce.

Entre las características comunicativas de Pinterest podemos distinguir la sencillez y la simplicidad, la posibilidad de poder marcar los precios en las imágenes, la oportunidad de viralizar los contenidos y multiplicar los efectos, la visualización directa del hipervínculo a la web de origen, la organización de los contenidos de manera que se exhiban claramente, la posibilidad de poder seguir un tablero en concreto o el menor reparo que muestran los usuarios en interactuar, al ser una red social mucho más visual que textual.

Es probable que, a raíz del hecho que entre las propiedades comunicativas de Pinterest no se recoja la posibilidad de comprar directamente desde la web de esta red social, el proceso de compra sea menos forzado y, por consiguiente, que se otorgue más libertad al prosumidor, consiguiendo así que éste utilice y ame la red social, decidiendo por él mismo qué, cuándo, dónde y cómo comprar.

\subsection{Pinterest como herramienta publicitaria}

Internet ha posibilitado estas relaciones 2.0, desde las que se fomenta este tipo de usuarios activos o prosumidores, al mismo tiempo que ha obligado a las empresas a convertirse en un internauta más, con el fin de poder participar en la comunicación virtual que les permita interactuar con sus consumidores o con clientes potenciales. En el entorno virtual en el que nos encontramos se demanda una conexión constante y transparente con la información a través de la red.

Por tanto, podemos discernir que, en el caso del comercio electrónico, no sólo es condición indispensable el acceso a Internet y al conocimiento necesario para su utilización, sino que también existen determinados artefactos comunicacionales que están fomentando esta clase de relaciones. Existen tres tendencias que generan el cambio del comercio electrónico: personalización, Pinterest y el iPad (Investigación OBS, 2012).

Bajo esta perspectiva, observamos cómo estas tres premisas han evolucionado la manera de comunicarnos y han transformado las interacciones de los internautas; el aquí y el ahora de Internet se han expandido gracias a los dispositivos móviles (tabletas, smartphones, phablets, es decir, la hibridación de los dos terminales anteriores), dando la oportunidad al individuo de comunicarse e informarse desde cualquier punto geográfico y en cualquier momento, y el auge de las redes sociales ha convertido las empresas en un internauta cercano, personificándolo para acabar con la imagen rígida y hermética de las compañías. 
En nuestro caso de estudio de la red social Pinterest, observamos cómo la personalización buscada por los usuarios, junto con la aparición de los dispositivos móviles con acceso a Internet, han sido dos aspectos claves para el desarrollo de esta red. Por un lado, los internautas buscan inspiración en Pinterest para crear una imagen personalizada de ellos mismos a través de fotografías, formando indirectamente un mapa visual de consumo y, por tanto, comunicando qué es lo que tienen o lo que desearían tener. Así, las empresas pueden contar con estos perfiles visuales de usuarios para conocer como éstos se relacionan con su marca o con sus productos.

De esta manera, las empresas pueden utilizar Pinterest como una herramienta no sólo para darse a conocer, sino también para estudiar a su target y para intentar focalizar sus mensajes en función de las necesidades y deseos de ese público objetivo. En definitiva, pueden trabajar con Pinterest de manera similar a como lo harían en un canal publicitario, aunque los contenidos no son en ellos mismos un anuncio.

En el desarrollo de nuestra investigación hemos observado cómo los internautas percibían a Pinterest como un escaparate de productos. En una de las entrevistas se apuntaba que "la carga visual hace que los tablones puedan ser utilizados como escaparates por los comercios tanto tradicionales como online"; hemos contemplado la existencia de una vinculación comercial de los contenidos aparecidos en la red, ya que, como se señalaba en otra de las entrevistas realizadas, Pinterest "permite a las marcas promocionar productos mediante la muestra de contenido audiovisual"; sin embargo, pese a que los usuarios son conscientes de la existencia de perfiles de empresas en esta red social, en ningún caso han mostrado la más mínima apreciación de que exista publicidad o mensajes propagandísticos. De hecho, reconocen que, al menos por el momento, es una de las pocas redes sociales que no incluye anuncios.

No obstante, aunque las compañías pueden desarrollar contenido publicitario o promocional para subir a Pinterest, el objetivo de comunicación de dicho contenido versa en la información, la simpleza y la claridad (aunque pueda tener rasgos publicitarios sutiles o encubiertos).

Así, la comunicación empresarial en redes sociales tiende a ser lo más clara, simétrica y bidireccional posible, con la intención de tratar con los usuarios de igual a igual, ofreciéndoles toda la información que necesiten, intentando crear lazos de confianza con ellos y emitiendo una imagen de igualdad de poderes, para que sean ellos, con todos los datos en su mano, quienes determinen pasar a la acción de compra en un clima de armonía.

De esta manera, los usuarios de Pinterest han declarado que este sitio web ofrece una imagen clara, sencilla y amigable, por lo que podríamos señalar que se trata de un lugar idóneo para que las empresas realicen este tipo de comunicación. Por tanto, el perfil de las empresas en Pinterest, ya sea a través de business o través de un perfil de usuario, está más enfocado en actuar como un relaciones públicas que como un canal publicitario. 
Según una de las personas entrevistadas durante el periodo de investigación, las claves de comunicación de Pinterest advierten que "son un canal más que puede ser aprovechado por las empresas para dar a conocer sus inventarios y, en algunos casos, para derivar tráfico a sus plataformas de comercio electrónico. Son un escaparate que, si se sabe utilizar, puede generar serias oportunidades de negocio".

Por tanto, podemos distinguir aquí también que Pinterest no es en sí un lugar de venta online, ni tampoco un tablón estrictamente publicitario; pero, por sus características, es el emplazamiento ideal para comenzar a gestar una posible venta, que se cerrará, en todo caso, en la web de procedencia del contenido, ya que, si el usuario desea pasar a la acción de compra, se dirigirá allí a través del hipervínculo insertado en la imagen de Pinterest.

\subsection{Pinterest como herramienta comunicacional}

La comunicación que se origina en Pinterest puede ser clasificada en dos vías generales, pese a que, ante todo, priman las interacciones de igual a igual entre empresas y usuarios.

Por un lado, hemos observado cómo el objetivo comunicacional de los usuarios es intercambiar información de forma abierta y desinteresada con el resto de la comunidad virtual, con la intención de obtener inspiración e ideas que les ayuden a formar su lista de deseos en Pinterest.

Por otro lado, advertimos también que el objetivo de comunicación de las empresas en esta red social es ofrecer información sobre sus marcas y productos, y facilitar ese contenido que los usuarios están buscando. Es decir, proporcionando una comunicación constante de etail (everywhere + retail), para que los cibernautas cuenten con toda la información necesaria sobre una empresa en la red, acercándoles y facilitándoles el proceso de compra.

Aunque el proceso de compra no se realiza en la página de Pinterest, es allí donde las empresas pueden realizar la primera toma de contacto con los clientes y, por tanto, la comunicación que allí se facilite podrá determinar la continuidad de la interacción. Es por eso que, aunque no podemos hablar estrictamente de Pinterest como una herramienta comunicacional para fomentar el e-commerce, nuestra investigación nos ha mostrado que esta red social tiene unas claras vinculaciones a las compras online, puesto que facilita a sus usuarios la posibilidad de dirigirse, con sólo un clic, a la web donde finalmente puede concluir la compra.

Por tanto, dada la correlación entre Pinterest y el e-commerce que hemos podido apreciar durante la investigación cualitativa, no podemos negar rotundamente esta vinculación, ya que, examinando los datos, podemos distinguir que no se trata de comercio electrónico en su significado etimológico, sino de social commerce. Es decir, Pinterest actúa como una herramienta comunicacional para el social commerce, dado que éste se caracteriza por la interacción entre cibernautas, a través de una red social, para aconsejar o recomendar productos o servicios, para compartir las listas de deseos, funcionando de forma colaborativa y siempre con fines comerciales. 
En el siguiente extracto de una entrevista realizada durante el proceso de investigación, el entrevistado considera que, en un futuro cercano, el social commerce se implantará con decisión en este tipo de redes sociales: "Pienso que en un futuro puede ser interesante como herramienta para el e-commerce, al igual que el social commerce adquirirá madurez en los próximos años. Ya existen herramientas como Shopinterest que permiten utilizar Pinterest a modo de e-commerce, pero de momento el objetivo principal es redirigir tráfico a la web. Según estudios, Pinterest, gracias al fuerte engagement que produce el contenido audiovisual, es una red que permite niveles altos de conversión" (extracto de entrevista realizada el 18 de noviembre de 2012 para la investigación cualitativa).

Así pues, Pinterest es una plataforma idónea para el social shopping, donde los usuarios y prosumidores pueden desarrollar una comunicación basada en el intercambio desinteresado de información con fines comerciales para que los internautas cuenten con el conocimiento necesario sobre bienes y servicios que les otorgue la suficiencia requerida para tomar decisiones de compra fundamentadas en la experiencia de otros usuarios.

Asimismo, el sistema de comunicación basado en etiquetas o hashtags, así como la descripción personal que los usuarios de Pinterest hacen sobre el contenido, fomenta la comunicación perfecta para el desarrollo de la web 3.0 o web semántica, que ofrecerá al usuario un mayor dominio de la red.

\section{Conclusión}

Los datos que hemos ido interpretado a lo largo de la investigación cualitativa, bajo el método de la teoría fundamentada, nos muestran que los internautas perciben a Pinterest como una herramienta comunicacional, pero no para fomentar intrínsecamente el comercio electrónico, sino para redirigir tráfico hacia otras webs. Por tanto, son las webs de empresas por sí mismas las que actúan como una herramienta para impulsar el comercio electrónico.

No obstante, en general, Pinterest es una red social vinculada directamente al social shopping, ya que sus características la posicionan como la red idónea para dar a conocer productos, por su diseño simple, visual y cuidado, que actúa como un escaparate de productos, donde los internautas pueden compartir y archivar aquellas ideas o productos que les gustan o que desearían tener a través de una organización por medio de tableros. Asimismo, las funciones de esta red social, que permiten marcar el precio en las imágenes e hipervincularlas a la web de origen, facilitan que, en el momento en el que el usuario lo desee, pueda dirigirse a dicha información para realizar una compra o para consultar los datos que necesite sobre un producto o servicio.

Por tanto, y dado que, por el momento, no se pueden realizar compras directamente desde la página de Pinterest, no podemos vincularla estrictamente al e-commerce, ya que simplemente actúa como un puente de enlace en favor de las webs, guiando flujos de internautas hacia ellas. 
Las limitaciones provienen sobre todo de la obligada falta de perspectiva sobre el objeto de estudio tratado (por su carácter reciente) y de la cifra de internautas (ampliable en el futuro) sobre la que se ha desarrollado la investigación, lo que conduce a plantear futuros análisis a lo largo del tiempo o teniendo en cuenta características cualitativas determinadas. Ello podría conducir a establecer correlaciones que, pese al carácter relativamente coetáneo del objeto de estudio, podrían aportar valor a la empresa, al efecto de monetizar sus inversiones en Pinterest y, en general, en redes sociales. Se trata de un reto para el que las aportaciones empíricas deben facilitar el camino.

\section{Bibliografía}

Álvarez, L. (2012): “Pinterest: alfabetització digital i artística a l'aula”, Guix: Elements d'acció educativa, n. 389, pp. 71-72.

Baugh, J. B.; Hallcom, A. S; Harris, M. E. (2010): “Computer assisted qualitative data analysis software: a practical perspective for applied research”, Revista del Instituto Internacional de Costos, n. 6, enero/junio 2010, pp. 69-81.

Bizrate Insights (2012): Online Consumer Pulse. Pinterest vs. Facebook: Which Social Sharing Site Wins at Shopping Engagement? Disponible en:http://bizrateinsights.com/blog/2012/10/15/online-consumer-pulse-pinterest-vs-facebookwhich-social-sharing-site-wins-at-shopping-engagement/ [Consultado el 12-01-2013].

Capgemini (2012): Digital Shopper Relevancy. Profiting from Your Customers' Desired All-Channel Experience. Paris: Capgemini.

Caines, M. (2012): “What Pinterest means for the arts", The Guardian, 24-II-12.

Cantalapiedra, C. (2012): Pinterest, ¿ Una herramienta de comercio electrónico?, Anuncios: Semanario de publicidad y marketing, 1409: 22-23.

ComScore (2013): 2013 Digital Wallets \& Payments Sneak Peek. Reston: comScore.

eMarketer (2012): Pinterest's Social Commerce Potencial: What Brands and Retailers Need to Know. New York: eMarketer.

Estalella, A. y Ardévol, E. (2010): “Internet: instrumento de investigación y campo de estudio para la antropología visuall”, Revista Chilena de Antropología Visual, n. 15, pp. 1-21.

Fondevila, J. F. (2010a): “El cloud journalism: un nuevo concepto de producción para el periodismo del siglo XXI”, Observatorio $\left(O B S^{*}\right)$ Journal, vol 4, n. 1, pp. 19-35.

- (2010b): "Multimedia, digital press and journalistic genres in Catalonia and in Spain: an empirical analysis", Communication Studies Journal, n. 7, pp. 81-95.

- (2011): “Aplicación semántica de la hipertextualidad en la prensa digital en España”, en Verón, J. J. y Sabés, F. (eds.): La investigación en periodismo digital. Algunos trabajos desde el ámbito universitario. XII Congreso de Periodismo Digital de Huesca-2011. Huesca: Asociación de la Prensa de Aragón, pp. 169-180. 


\section{- (2012a): The Broadband Society in the World. Terrassa: CECABLE.}

- (2012b): "El social commerce, al alza”, Telecomunicaciones y Periodismo, http://telecomunicacionesyperiodismo.blogspot.com.es/2012/11/el-social-commerce-al-alza.html [Consultado el 11-01-2013].

Fondevila, J. F. y Beriain, A. (2012): “La interactividad en medios sociales: un estudio de caso", Revista Internacional de Ciencias Sociales Interdisciplinares, vol. 1, n. 2, pp. 25-44.

Fondevila, J. F; Carreras, M.; Del Olmo, J. L. (2012): "Fuentes de información y elección de universidad: el caso catalán", Didáctica, Innovación y Multimedia, año 8, nº 24.

Fondevila, J. F.; Del Olmo, J. L.; Bravo, V. (2012): "Presencia y reputación digital en social media: comparativa en el sector de la moda", Fonseca, Journal of Communication, n. 5 (Diciembre de 2012), pp. 92-116.

Fonoll, J. (2012): Pinterest: la mayor 'wishlist' del mundo, Anuncios: Semanario de publicidad y marketing, no 1414, p. 6.

Investigación OBS (2012): “Las tres P’s del eCommerce: Personalización, Pinterest y iPad”, Tendencias e Innovación, 07-062012. Disponible en: http://investigacionobs.wordpress.com/2012/06/07/las-tres-ps-del-ecommerce-personalizacion -pinterest-y-ipad/ [Consultado el 12-01-2013].

Islas-Carmona, J. O. (2008): "El prosumidor. El actor comunicativo de la sociedad de la ubicuidad", Palabra Clave, Universidad de La Sabana.

Kotler, P. y Armstrong, G. (2003): Fundamentos de Marketing. Madrid: Pearson Educación.

Ledbetter, E. (2012): “Pinterest Demographic Data: The Marketers Guide to People Who Pin”, Ignite Social Media, 24-01-12. Disponible en: http://www.ignitesocialmedia.com/social-networks/pinterest-demographic-data/ [Consultado el 12-012013].

Marketing Directo (2012): "Pinterest es la niña bonita del e-commerce", Marketing Directo, 12-6-12. Disponible en: http://www.marketingdirecto.com/actualidad/digital/pinterest-es-la-nina-bonita-del-e-commerce/ [Consultado el 1201-2013].

McCracken, G (2012): “Pinterest as Free Market Research”, Harvard Business Review Blog Network, 17-2-2012. Disponible en: http://blogs.hbr.org/cs/2012/02/pinterest_is_free_market_resea.html [Consultado el 12-01-2013].

McLellan, E.; MacQueen, K.M.; Neidig, J. L. (2003): “Beyond the qualitative interview: Data preparation and transcription”. Field Methods, vol. 15, n. 1, pp. 63-84.

Moore, I (2005): Does Your Marketing Sell? The Secret of Effective Marketing Communications. Boston: Nicholas Brealey Publishing.

Núñez, C. (2012): El rincón innovaddoor: Pinterest, Facebook y otros category killers en Internet, Interactiva: Revista de la comunicación y el marketing digital, n. 133, p. 5.

ONTSI-Observatorio Nacional de las Telecomunicaciones y de la SI (2012): Las Redes Sociales en Internet. Madrid: ONTSI. 
Rapley, T. J. (2001): “The art(fulness) of open-ended interviewing: some considerations on analysing interviews", Qualitative Research, vol 1, n. 3, pp. 303-323.

Roig, A. (2012): “Captúrame, visualízame, compárteme: la revolución de las nuevas plataformas visuales colaborativas", COMeIN, Revista de los Estudios en Ciencias de la Información y la Comunicación. Barcelona: UOC.

Ruiz Olabuénaga, J. I. (1996): Metodología de la Investigación Cualitativa. Bilbao: Universidad de Deusto.

Solis, B. (2012): Pinterest Rivals Twitter in Referral Traffic. Disponible en: http://www.briansolis.com/2012/01/pinterestrivals-twitter-in-referral-traffic-pinteresting/ [consultado el 11-01-2013].

Strauss, A. y Corbin, J. (1998): Basics of Qualitative Research Techniques and Procedures for Developing Grounded Theory. London: Sage Publications.

Szymanski, J. (2012): “Pinterest Potential: User Collaboration”, Altimeter, 10-02-2012. Disponible en: http://www.altimetergroup.com/2012/02/pinterest-potential-user-collaboration.html [Consultado el 12-01-2013].

Taylor, S. J. y Bogdan, R. (1984): La observación participante en el campo y La entrevista en profundidad. Introducción a los métodos cualitativos de investigación. La búsqueda de significados. Barcelona: Paidós Ibérica.

Villar, A. (2012): Pinterest lidera las conversiones en las ventas online. Disponible en: http://abrahamvillar.es/2012/05/pinterest-lidera-las-conversiones-en-las-ventas-online/ [Consultado el 11-01-2013]. 